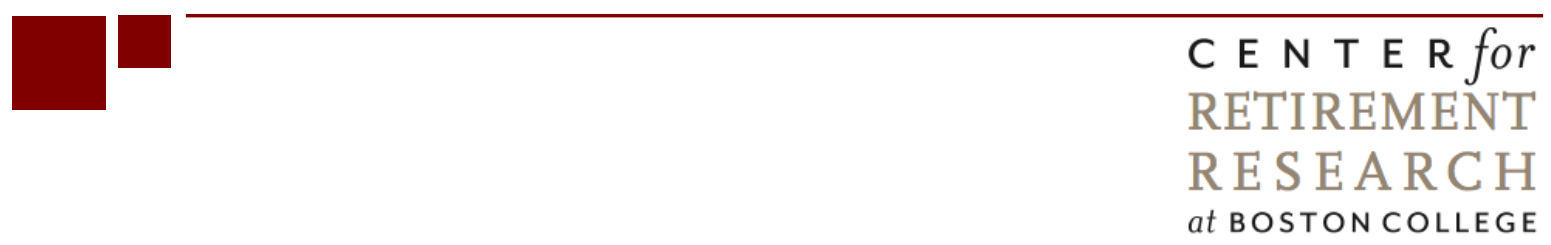

\title{
CAN THE GOVERNMENT INCENTIVIZE THE PURCHASE OF PRIVATE LONG-TERM CARE INSURANCE? EVIDENCE FROM THE LONG-TERM CARE PARTNERSHIP PROGRAM
}

\author{
Nadia Greenhalgh-Stanley
}

CRR WP 2012-14

Submitted: May 2012

Released: May 2012

\author{
Center for Retirement Research at Boston College \\ Hovey House \\ 140 Commonwealth Avenue \\ Chestnut Hill, MA 02467 \\ Tel: 617-552-1762 Fax: 617-552-0191 \\ http://crr.bc.edu
}

Nadia Greenhalgh-Stanley is an assistant professor in the department of economics at Kent State University. The research reported here was performed pursuant to a grant from the U.S. Social Security Administration (SSA) funded as part of the Retirement Research Consortium (RRC). The opinions and conclusion expressed are solely those of the author and do not represent the opinions or policy of SSA, any agency of the federal government, the RRC, Kent State University, or Boston College. The author would like to thank Gary Engelhardt and participants at the National Tax Association meetings for comments.

(C) 2012, by Nadia Greenhalgh-Stanley. All rights reserved. Short sections of text, not to exceed two paragraphs, may be quoted without explicit permission provided that full credit, including (C) notice, is given to the source. 


\begin{abstract}
About the Steven H. Sandell Grant Program
This paper received funding from the Steven H. Sandell Grant Program for Junior Scholars in Retirement Research. Established in 1999, the Sandell program's purpose is to promote research on retirement issues by scholars in a wide variety of disciplines, including actuarial science, demography, economics, finance, gerontology, political science, psychology, public administration, public policy, sociology, social work, and statistics. The program is funded through a grant from the Social Security Administration (SSA). For more information on the Sandell program, please visit our website at: http://crr.bc.edu/about-us/grant-programs/steven-hsandell-grant-program-2/ send e-mail to crr@bc.edu, or call Marina Tsiknis at (617) 552-1092.
\end{abstract}

\title{
About the Center for Retirement Research
}

The Center for Retirement Research at Boston College, part of a consortium that includes parallel centers at the University of Michigan and the National Bureau of Economic Research, was established in 1998 through a grant from the Social Security Administration. The Center's mission is to produce first-class research and forge a strong link between the academic community and decision-makers in the public and private sectors around an issue of critical importance to the nation's future. To achieve this mission, the Center sponsors a wide variety of research projects, transmits new findings to a broad audience, trains new scholars, and broadens access to valuable data sources.

Center for Retirement Research at Boston College

Hovey House

140 Commonwealth Avenue

Chestnut Hill, MA 02467

phone: 617-552-1762 fax: 617-552-0191

e-mail: crr@bc.edu

crr.bc.edu

Affiliated Institutions:

The Brookings Institution

Massachusetts Institute of Technology

Syracuse University

Urban Institute 


\begin{abstract}
While the private long-term care insurance market has remained small, an important trend in the United States has been the increased dependence on Medicaid to provide long-term care services for the elderly. As a result, the government has attempted to develop laws that would incentivize the purchase of private long-term care insurance policies, in order to at least initially shift some of the financial burden away from Medicaid. The Deficit Reduction Act of 2005 (DRA05) allowed states to adopt Long-Term Care Partnership (LTCP) programs, which provided incentives for individuals to purchase private long-term care insurance policies by decreasing the implicit tax the elderly face for holding financial and non-housing assets. However, the literature to date has little empirical evidence on whether the government has been successful in expanding the private long-term care insurance market. Using the Health and Retirement Study (HRS) and state-by-time variation in adoption of LTCPs, I find that state adoption of these programs increased the incidence of having long-term care insurance by 3 percent and decreased Medicaid use among respondents by 18 percent. Additionally, I find an increase in private long-term care insurance policies that provide nursing home care and a decrease in plans that provide in-home care. These results are especially important with the recent OAA and CLASS legislation.
\end{abstract}




\section{Introduction}

The elderly are the fastest growing population in the United States, with approximately 6.8 million of them needing long-term care services in 2009 (RWJ, 2011). In 2000, the average annual nursing home cost was \$50,000 and Dick et al (1994) found that conditional on needing a nursing home, 12 percent will need it for five or more years. In addition, according to the Robert Wood Johnson Foundation, 67 percent will need some type of long-term care during their lifetime. Present value calculations of the long-term care costs facing the elderly would exhaust the resources of the average elderly asset portfolio. As a result, many have been ill-prepared to pay these costs out-of-pocket and have instead relied on Medicaid to pay for and provide their needed long-term care. According to the Centers for Medicaid and Medicare Services, in 2005 national spending on nursing home reached $\$ 122$ billion, with 43.9 percent of this coming from Medicaid.

Simultaneously, the private long-term care insurance market has remained small due to documented demand and supply side failures in the literature. ${ }^{1}$ This can be illustrated by the fact that in 2000, Medicaid paid out \$31 billion for nursing home expenditures, while the private long-term care insurance market only paid out \$300 million in long-term care expenditures. The private long-term care insurance market has remained small for a number of reasons including adverse selection, Medicaid crowd out, and numerous other market failures, which suggest there may be a place for the government to step in and improve market conditions and efficiency. Clearly Medicaid is the most important provider of long-term care in the United States, which has led to interest among policy makers and federal and state governments to find ways to expand this market in order to ease government budgets and shift some of the financial burden of long-term care costs away from Medicaid. $^{2}$

Unfortunately, while there is evidence in the economics literature demonstrating that Medicaid crowds out demand for private long-term care insurance due to its nature as a payer of last resort, the literature has largely ignored any analysis of government policies that may in fact increase demand for private long-term care insurance, with the exception of tax subsidies (Goda, 2010). ${ }^{3}$ I contribute to the literature by exploiting recent state-by-calendar-year level variation in

\footnotetext{
${ }^{1}$ See Brown and Finkelstein (2007).

${ }^{2}$ Medicaid nursing home expenditures are the second highest expenditure on state budgets after public education.

${ }^{3}$ See Brown, Coe, and Finkelstein (2007) and Brown and Finkelstein (2008) for evidence of Medicaid crowd out of the private long-term care insurance market.
} 
state adoption of Long-Term Care Partnership (LTCP) programs. In the Deficient Reduction Act of 2005 (DRA05), Congress allowed states to adopt LTCP programs, which incentivized the purchase of long-term care insurance by allowing individuals to shelter their assets from Medicaid spend down should they ever need Medicaid to provide long-term care services in addition to those provided by their private policy. Prior to adoption of this law (except in four grandfathered in states), individuals needing Medicaid after exhausting their private long-term care benefits would have to spend down their remaining assets and income to meet Medicaid spend-down thresholds. As a result, DRA05 set up incentives for elderly individuals to buy long-term care insurance policies by decreasing the implicit tax of holding financial assets. I use the Health and Retirement Study (HRS) data and exploit state-by-time variation in these policies to see if they were successful at incentivizing the purchase of private long-term care insurance policies.

This paper contributes to the literature in four ways. First, to the best of my knowledge I am the first to examine whether LTCP programs increased the number of policies purchased (as the government intended for them to) and increased the incidence of the elderly who have these policies. This question has important policy implications for future policies aimed to increase demand, expand the historically small private long-term care insurance market, and ease the burden on Medicaid. Second, the HRS allows me to investigate what type of plans individuals bought (i.e. nursing home only plans or in-home care only plans). This is particularly relevant in light of recent legislation including the Older Americans Act (OAA), which aims to shift longterm care use from expensive nursing homes to less expensive in-home and community based care (n4A, 2011), and the CLASS Act, which aims to pay out \$50/day to allow individuals to contribute to the cost of in-home care, nursing home care, or informal care through a more widely used long-term care insurance model. However, legislation requires the CLASS Act to demonstrate sufficiency and setting proper premium pricing to deter adverse selection and moral hazard problems (RWJ, 2011).

Third, the literature has found evidence that the government provision of long-term care services through Medicaid crowds out demand for private long-term care insurance and therefore puts more pressure on state Medicaid budgets. It is possible that state adoption of LTCP programs will cause the benefits of purchasing a private long-term care policy to outweigh the costs of having “double” coverage with Medicaid, which would reduce Medicaid's crowd out of 
demand for private long-term care insurance and has not yet been considered in the literature. Finally, the answers to the questions of interest will have important policy implications. Federal and state governments are looking for ways to recoup costs, ease state Medicaid budgets, and increase demand for private long-term care insurance through programs, such as a federal mandate for estate recovery programs (Omnibus Budget Reconciliation Act of 1993) and longterm care partnership programs (DRA05). Measuring the impact of these policies will help shape future laws and potentially change the size and composition of the private long-term care insurance market.

Preliminary estimates show that state adoption of LTC Partnerships caused the elderly to increase the purchase of long-term care insurance by 3.0 percent. ${ }^{4}$ More specifically, state adoption of long-term care partnerships resulted in the elderly buying more nursing home care only private insurance policies and less in-home care private insurance policies, which is counter to the aims of the OAA. In addition, LTCP programs decreased the reported use of Medicaid by 18 percent among those with a college education.

\section{Background Information}

\subsection{Long-Term Care Partnership Programs}

In the 1980s, the Partnership for Long-Term Care (LTCP) was established with the help and sponsorship of the Robert Wood Johnson Foundation. Essentially, the LTCP program allowed states to incentivize the purchase of private long-term care insurance policies by decreasing the implicit tax of holding assets. If an individual chose to buy a private long-term care insurance policy and lived in a state with a partnership program, then should they need additional long-term care services beyond what their private policy provided, they were exempt from Medicaid spend down rules and were allowed to keep their house, even if they lived in a state with an estate recovery program in place. In general, Medicaid spend down leaves single individuals with approximately $\$ 2,000$ in financial assets (owner-occupied housing and the primary vehicle are exempt from spend down) and income at about the Supplemental Security Income (SSI) level. However, in most states the elderly are allowed to contribute income and assets toward the cost of their healthcare (including nursing homes) each month, allowing elderly

\footnotetext{
${ }^{4}$ Marginal effects (\% change) $=$ percentage point change/sample mean.
} 
with significantly higher assets and income to be eligible for Medicaid and are known as the "Medically Needy". 5

State governments had the incentive to adopt these programs because it had the potential to ease some of the state long-term care costs paid by Medicaid and shifted the burden of care, at least initially, to the individual. In 1992, California, Connecticut, Indiana, and New York had programs in place. Each state was given the choice between a dollar-for-dollar program, which exempted individual assets from Medicaid spend-down eligibility to the exact dollar amount of coverage they purchased, or total asset protection plans, which protected all assets from spenddown eligibility thresholds (McCall et. al., 1997).

Congress later placed a ban on the adoption of LTCP programs in the Omnibus Reconciliation Act of 1993 (OBRA93), however the four states with programs already in place were grandfathered in. Medicaid spending on nursing homes alone increased from \$31 billion in 2000 to \$53.5 billion in 2005 (Centers for Medicaid and Medicare Services), and as a result of crippling state Medicaid budgets, Congress passed the Deficit Reduction Act of 2005 to lift this ban and allowed states to incentivize the purchase of private long-term care insurance policies as a way to relieve state Medicaid budgets. DRA05 does require certain specifications are met by the state plan and insurance companies. These include certain consumer protections and insurance regulations. LTCPs provided a way for individuals to protect assets and preserve bequest motives, while still receiving Medicaid long-term care services. In 2006 the 4 grandfathered in states had the programs in place and by 2008, 27 states had adopted them, increasing again to 34 states in 2010. Clearly, these programs are gaining in popularity, making it even more essential to understand whether these LTCPs actually resulted in more private policies being purchased.

While to date there is no evidence that the author is aware of on the impact of these Long-Term Care Partnership programs on the purchase of private long-term care insurance, lessons can be learned from the original four states that adopted these programs in 1992. By 2006, Connecticut residents had purchased 35,523 active long-term care insurance policies, of which 92 percent of these were reported to be first time purchasers according to the Connecticut Partnership for LTC. These policies accounted for $\$ 13,462,007$ in total asset protection and

\footnotetext{
${ }^{5}$ Other states instead choose to allow the elderly with income within 300\% of the SSI level be eligible, though those elderly cannot spend down their income on nursing home costs and still qualify due to the higher threshold they are given by their state.
} 
$\$ 3,515,771$ in asset protection for those who have accessed Medicaid or have an application pending. As of 2005, the four founding states had over 172,000 active partnership insurance policies, with approximately 1,209 of them receiving benefits at this time (RWJ, 2007). These facts seem to document a clear positive relationship between state adoption of Long-Term Care Partnership programs and the number of private long-term care insurance policies in those states. This is further supported by the fact that 92 percent of Connecticut's current policies are held by first time buyers, which could suggest that state adoption of long-term care insurance policies did indeed provide enough incentives to induce demand for these policies (RWJ, 2007). However, other factors could be varying over time, as a result, it is still of the utmost importance to use a regression framework to identify the effect of these programs on the private long-term care insurance market.

\subsection{Relevant Literature}

To date, there has not been any research in the economics literature investigating the impact of Long-Term Care Partnership programs on the private long-term care insurance market. However, there is evidence on the Partnership program from the health policy field and research done by the Robert Wood Johnson Foundation, as well as two particularly relevant strands of economics literature to consider. First, while the economics literature has not yet measured the effect of Partnership programs on the private long-term care insurance market, studies in the Health Policy field have investigated it. McCall et. al. (1997) find that 31 percent of partnership purchasers reported through a survey that without the presence of the Partnership program, they would have not purchased private long-term care insurance or would have been very unlikely to do so. This provides information that the elderly do respond to government incentives. They also found that through 1995, the partnerships had 12,698 policies and covered 38-74 percent of those covered in the four partnership states. Their findings suggest that on average those who purchase partnership policies were healthier, higher educated, wealthier, and were more active and knowledgeable financial planners. McCall et. al. (1998) concluded that factors important in expanding the number of partnership policies sold included improved education and knowledge. Interestingly, they also found that not burdening other family members was the main reported reason for the purchase of a partnership program. 
On the other hand, Moses (2001) found that the original program in four states did not increase the middle class purchase of private long-term care insurance because of the structure of Medicaid as it incentivizes both Medicaid estate planning and the loopholes for the elderly in the spend-down. For instance, the Medically Needy populations are eligible for Medicaid if their medical expenses (including nursing home care) exceed their current income, which can easily be done. For example, in 2004 per-capita spending was \$16,689 for those 75-84 and \$25,691 for those 85 and older and in 2000 the average cost of a nursing home was \$50,000. Alhstrom, Clemens, and Tomlinson found that while the number of policies did increase for the four states, the elderly with long-term care insurance ranged from 1.5 percent-5.7 percent, which was still significantly less than the national average (around 10 percent).

Second, the economics literature has shed light on the reason for the historically small private long-term care insurance market, both through documented supply and demand-side failures in the market (Brown and Finkelstein, 2007). Gleckman (2007) concludes that the current structure of the private long-term care insurance market and its interaction with Medicaid make it unlikely for this market to expand. In addition, the interaction between the public (Medicaid) and private long-term care insurance markets has led to the crowd out of private long-term care insurance through Medicaid’s design as a payer of last resort (Brown, Coe, and Finkelstein, 2007 and Brown and Finkelstein, 2008). However, to date the literature has not yet investigated whether government policies aimed to incentivize the purchase of private long-term care insurance have been successful in reducing Medicaid's crowd-out of private policies. More specifically, it is possible that the Partnerships protection of assets (lowering the implicit tax on financial assets for Medicaid spend-down to zero for the Asset Model states and to dollar for dollar protection in the other states) and its interaction with spend down could actually substantially increase the size of the private long-term care insurance market.

Third, the economics literature has investigated the effect of other government policies on the private long-term care insurance market (Goda, 2010) and in-home and informal longterm care. Goda (2010) measured the effect of tax subsidies on the private long-term care insurance market. She finds a 28 percent increase in purchase rates when a state adopts the average tax subsidy, but that the majority of the response comes from higher asset and income individuals (those less likely to use Medicaid). Next, McKnight (2007), Orsini (2010), and Engelhardt and Greenhalgh-Stanley (2010) all find that the movement to a prospective payments 
system from a retrospective payments system for Medicare home health aids significantly altered access to Medicare home health aides (in-home care) and shifted care towards informal care via shared living arrangements.

\section{Data and Methodology}

I exploit state-by-time variation in state adoption of LTCP programs to determine whether long-term care partnership programs increased the number of policies purchased (as the government intended for them to). This question has important policy implications for future policies aimed to increase demand and expand the historically small private long-term care insurance market. Subsequent questions of interest measure whether long-term care partnerships increased the purchase of specific types of private policies more than others. There is data available in the HRS that breaks down private long-term care insurance policies into four categories.

State adoption of Long-Term Care Partnership programs makes the purchase of private long-term care insurance more attractive to individuals for three reasons. First and second, even if the individual later requires Medicaid to provide additional long-term care services needed, that individual's assets are protected from Medicaid spend-down laws and therefore are not required to spend-down all of their wealth, i.e. become impoverished, to qualify for Medicaid provision of needed services. In other words, the implicit tax of holding financial assets decreased (as housing assets are always exempt from spend down). Lastly, if the individual lives in a state with an estate recovery program and use Medicaid to pay for some of their long-term care services, the state will never go after the value of the house. This helps protect bequest motives and is especially important because owner-occupied housing is the largest non-pension asset for the elderly (Munnell and Soto, 2005).

This is an empirical question as state adoption of LTCP programs could either increase private long-term care insurance plans or have no effect on the market. This paper is distinctive because finding that adoption of these programs increased the number of policies purchased would provide new evidence that the government succeeded in their intended goal. On the other hand, finding no effect or that the government did not succeed in their target to increase policies 
would also be new and valuable evidence, because it would help economists understand the incentives and help policy makers shape future laws.

Overall if the elderly are responsive to incentives provided by states to buy private longterm care insurance, then the timing of the adoption of Long-Term Care Partnership programs should have affected the incidence of private long-term care insurance policies and the percentage of the elderly in a state with private long-term care insurance policies. To examine this empirically, let $i, s$, and $t$ index household, state, and calendar-year respectively. Individual demographic variables are included in the vector $\mathbf{X}$. Then the levels of private long-term care insurance policy equation is

$$
D_{\text {ist }}^{\text {LTC Insurance }}=\beta \mathrm{D}_{\mathrm{st}}^{\mathrm{LTCP}}+\boldsymbol{X}_{\text {ist }}+\gamma_{s}+\phi_{t}+u_{\text {ist }},
$$

where $D^{\text {LTC Insurance }}$ is a dummy variable that takes on value of one if the person purchased a private long-term care insurance policy, $D^{L T C P}$ is a dummy variable that takes on a value of one if the state has a Long-Term Care Partnership program in place and zero otherwise, $\gamma$ is a full set of state fixed effects, $\phi$ is a full set of calendar-year fixed effects, and $u$ is a disturbance term. In addition, $\mathbf{X}$ includes dummy variables for gender, non-white, college degree or higher, as well as age, number of children, and number of independent activities of daily living. State fixed effects will control for all time-invariant state specific characteristics, and the calendar-year fixed effects are particularly important over a long time period and will control for years with recessions and booms.

I estimate the parameters in equation (1) using the Health and Retirement Study (HRS). The HRS is a pre-eminent data set in economics and demographics on aging. It collects a wealth of information on family structure, wealth portfolios, and demographics for a large elderly sample. The AHEAD cohort consists of elderly individuals seventy and older in 1993. The original HRS cohort consists of elderly individuals fifty-five and older in 1992. New cohorts of younger generations are added later in the data set and will be used as well. Each respondent is surveyed every two years. I focus on the younger cohort because private long-term care insurance policies are typically bought prior to the age of seventy. Because I am relying on state-by-time variation for identification, I need to use the restricted-access geo-code HRS data to attach the state of residence to each recipient. I use the 2002-2008 (add in 2010 when it becomes available) data from the RAND and HRS data sets. I then create a panel data set from the HRS unrestricted and restricted data sets. The RAND data, which is a compilation of 
variables from the unrestricted HRS, also allows for me to test whether different types of longterm care policies increased in number, i.e. those that covered in-home care only, nursing home care only, or both. The data for Long-Term Care Partnerships come from various sources including state Medicaid directors and the Robert Wood Johnson Foundation. From 2002 to 2006 there were only the four grandfathered in states with policies, in 2008 there were 27 states with programs in place, and by 2010 seven additional states had adopted them. However, it is possible that response time is slow because of the necessary research and application process. As a result, I also estimate equation (1) two years after the law change to see if there is a lagged response (this will be done once the 2010 state identifiers are available). Sample statistics are provided in Table 1.

\section{Results}

The 2010 HRS state identifiers were originally scheduled to be released in March 2010, but there was a delay and they still have not been released as of October, 2011. As a result, I am missing a significant amount of variation (seven additional states adopted LTC Partnership programs between 2008 and 2010 and states only added these programs in 2008 and 2010). Most of the results presented in the current draft of the paper are insignificant, but I believe that adding in 2010 will give me more variation and observations and allow me to find significant results. I also believe that there may be a lag between when the state adopted their program and when we see the elderly begin to increase their purchase of private long-term care insurance policies. I cannot test this theory until I have the added 2010 data. The 2010 state identifiers will allow me to add variation and perform numerous robustness checks about a potential lagged response to the law change and to test for the endogeneity of adoption of these state programs. I will talk in detail about the current results and their point estimates, while acknowledging that they are insignificant and will change when the 2010 identifiers are released.

\subsection{Long-Term Care Insurance Policies}

Table 2 presents the results of estimating equation (1) using a dummy variable indicating whether either person (the respondent or spouse) in a household purchased a private long-term care insurance policy as the dependent variable. For all results presented, the standard errors are 
clustered by both state and person identifier using the Cameron, Gelbach, and Miller (2006) clustering technique. Column (1) shows that state adoption of a long-term care partnership program increases the household having a private long-term care insurance plan by 0.4 percentage points. With a sample mean of 13.63 percent, the marginal effect is that state adoption of these programs increased the purchase of private long-term care insurance policies by 3.0 percent. While this result is insignificant (adding in additional variation in 2010 should help with this problem), it does present evidence that the best guess is that state Long-Term Care Partnership programs did increase the incidence of having a private long-term care insurance policy.

Column (2) shows the same regression for only those with a college education. Presumably private long-term care insurance plans, which provide partial or total wealth insurance (depending on whether the state has a dollar-for-dollar program or not) is only beneficial for those with wealth to protect. However, I cannot cut my sample based on wealth or include it as an explanatory variable in the regression because of endogeneity issues, as it is correlated with the discount rate. Instead, I can consider only those with a college education or more. Column (2) presents these results. LTCP programs result in those with a college education or more increasing the purchase of a private long-term care insurance plan by 0.009 percentage points or 4.7 percent, which provides evidence that those that value it the most are the ones increasing their purchase of private long-term care policies. Column (3) shows the estimation for a high school education or more and again shows a higher rate of purchase than for the entire sample (regardless of education attainment) shown in Column (1). Table 2 provides evidence that state adoption of LTC Partnership Programs has provided incentives to buy private long-term care insurance plans and that the elderly have responded. Again while the results are currently insignificant because of the absence of the 2010 variation, the point estimates provide the best guess that there is a positive relationship between LTC Partnership programs and the incidence of private long-term care insurance plans.

\subsection{Type of Long-Term Care Insurance Plan}

The HRS provides information that allows for the general breakdown of what type of private long-term care insurance plans was purchased, those that cover nursing home care, those that cover in-home care, those that cover both, and those with other coverage. Only a small part 
of the sample has policies that only cover nursing home care (2.22 percent), but nursing home care is the most expensive form of long-term care with a fast growth rate and is usually provided by Medicaid. Recent legislation including OAA and CLASS have also aimed to shift long-term care toward in-home or community based care and away from the more expensive nursing home care. Column (1) of Table 3 shows that adoption of LTC Partnership programs results in the elderly increasing nursing home only policies by 0.003 percentage points or 13.6 percent. Conditional on having a private long-term insurance plan, column (2) shows state adoption of LTC Partnership programs increases nursing home only programs by 13.7 percent. Columns (3) and (4) provide statistically significant evidence that the elderly buy less in-home only care insurance policies after state adoption of LTC Partnership programs. Table 3 shows that LTC Partnerships are resulting in more nursing home plans being purchased and less in-home care only plans being purchased, which is contradictory to the aims of OAA.

\subsection{Medicaid Use}

Table 4 presents linear probability evidence of state adoption of LTC Partnership programs on the elderly reporting that they are enrolled in Medicaid. ${ }^{6}$ One of the aims of LTC Partnership programs was to shift some of the burden of nursing home costs at least initially off of state Medicaid budgets and towards the individual. State adoption of these programs could increase Medicaid use because it decreased the implicit tax of going on Medicaid by allowing financial assets to be sheltered or it could decrease Medicaid use because now more individuals have private long-term care insurance plans and do not need Medicaid as they do not exhaust their private benefits. It is also possible that crowd out of private long-term care insurance decreased due to Medicaid. As a result, it is an empirical question that is investigated by estimating equation (1) with Medicaid use as the dependent dummy variable. Column (1) provided evidence for whether either person in the household uses Medicaid, column (2) is whether the respondent uses it, and column (3) is whether their spouse uses it. All three columns show that state adoption of LTC Partnership programs decreased the use of Medicaid, with columns 1 and 2 showing statistically significant decreases of 18.1 percent and 22 percent, respectively.

\footnotetext{
${ }^{6}$ I do linear probability because of small states that may present convergence problems with probit or logit. I feel it is better to run linear probability than have a selected sample based on state size.
} 


\subsection{Individual Fixed Effects}

Table 5 provides the results for an individual fixed effects regression analysis. Consider instead the following equation:

$$
\text { (2) } Y_{i s t}=D_{s t}^{L T C P}+X_{i s t}+\emptyset_{t}+\theta_{i}+u_{i s t}
$$

where the equation takes out unobserved individual characteristics and shows the effect of state adoption of LTC Partnership programs on four different dependent variables including having ltc insurance, the type of insurance, and using Medicaid. This analysis accounts for individual trends (individual fixed effects) and year trends (year fixed effects). It also controls for any demographic variables that change over time, which is only marital status from equation (1). In addition, I control for age as the respondents are different ages in the beginning of my sample in 2002. Age is also an important factor as all elderly might be increasing their purchase of private long-term care insurance as they get older and start thinking about their needs but it may be confounded because states also adopted LTC Partnership programs at a higher rate over time. Alternatively, age could affect the purchase in the opposite direction because of adverse selection, plans do not want to insure those that are older and will assume individuals have private information that they will definitely need nursing home care. This analysis allows me to control for the effect of older individuals buying these plans more over time regardless of whether their state adopted a LTCP program or not. As a result, I am left with the unbiased effect of state adoption on these dependent variables.

All four columns of Table 5 and their associated results confirm the findings using equation (1) and Tables 2-4. Using an individual fixed effects method, state adoption of LTC Partnership programs has a positive relationship with having a private long-term care insurance policy and having nursing home care policies, and has a negative relationship with purchasing in-home care only policies and using Medicaid (statistically significant). These provide robustness checks of the initial results.

\subsection{Robustness Checks and Lagged Results}

It is definitely a possibility that it takes time after state adoption of LTC Partnership programs for the elderly to start buying these policies. I would expect to see even larger effects two years after the law change. However, until the 2010 state identifiers are released I cannot carry out this analysis because essentially all of the state-by-time variation in adoption of these 
plans is from 2008 and 2010. I also can use robustness checks to test for the possible endogeneity of when the states decide to adopt these plans, by using placebo tests.

\section{Conclusions}

Recently the elderly have increased in number, life expectancy, and need for long-term care services at the end of life. Traditionally, Medicaid has been the largest provider of these services as the private long-term care insurance market has remained relatively small. Pressure on state budgets and increasing costs have resulted in the government trying to get creative and develop ways to expand the private long-term care insurance market by incentivizing the purchase of policies to take some of the financial burden off of Medicaid. One of these policies is the Long-Term Care Partnership program, which allows the elderly to shelter financial assets. To date research has not yet investigated whether the government was successful in incentivizing the purchase of these policies. This is especially important in light of future changes in the market from the proposed healthcare reforms, OAA, and CLASS Act and as both healthcare and nursing home care costs continue to rise.

I find that state adoption of these programs does increase the purchase of private longterm care insurance plans by about 3 percent and decreases the elderly on Medicaid by about 18 percent. I also find evidence that these partnerships result in more nursing home care policies being purchased and fewer in-home care policies purchased. This has important policy implications that the government can potentially increase the size of the private long-term care insurance market and potentially decrease Medicaid's crowd out as a payer of last resort. These results are for the college education population, who have financial assets to protect.

Other policy implications include the Older Americans Act, which aims to shift longterm care services from more expensive nursing home care to less expensive in home care through aids or informal care through family members. However, Medicare shifted home health aid reimbursement from a retrospective payment system to a prospective payment system which changed in home care (McKnight, 2007; Engelhardt and Greenhalgh-Stanley, 2010; Orsini, 2010). This paper provided evidence that the DRA05 resulted in an increased presence of nursing home plans and actually decreased the number of in-home care plans purchased. The OAA will be eligible for re-authorization in late 2011 and likely again 3-4 years after that, which 
the evidence provided in this paper can provide policy perspective to consider. Especially as there has been an increased demand for services and will continue to be as the babyboomers get set to retire.

Future extensions to this paper include most importantly adding in 2010 state identifiers when they are released to exploit all of the state-by-time variation in state adoption, looking at a different sample, and estimating if these effects increase as more time has elapsed after the adoption of these programs. Research should also consider the premium prices in the expanded private long-term care insurance market, possible expansion of policies to entice middle class families to purchase them, and investigation into adverse selection and moral hazard problems in the expanded market. 


\section{References}

Ahlstrom, Alexis, Emily Clements, and Anne Tumlinson, “The Long-Term Care Partnership Program: Issues and Options” Papers for the Retirement Security Project.

Brown, Jeffrey R. and Amy Finkelstein, "Why is the Market for Long-Term Care Insurance so Small?” Journal of Public Economics 91(2007): 1967-1991.

Brown, Jeffrey R. and Amy Finkelstein, “The Interaction of Public and Private Insurance: Medicaid and the Long-Term Insurance Market.” American Economic Review 98(2008): 1083-1102.

Brown, Jeffrey R., Norma B. Coe, and Amy Finkelstein, "Medicaid Crowd-Out of Private Long Term Care Insurance Demand: Evidence from the Health and Retirement Survey.” Tax Policy and the Economy 21(2007): 1-34.

Cameron, A., Gelbach, J., Miller, D., 2006. Robust Inference with Multi Way Clustering, NBER Working Paper No. T0327.

Center for Medicaid and Medicare Services, National Health Expenditures. Connecticut Partnership for LTC, June 30, 2006.

Dick, Andrew, Alan M. Garber, and Thomas A. MaCurdy, in David Wise (ed.) Studies in the Economics of Aging, 1994.

Engelhardt, G., Greenhalgh-Stanley, N., 2010. Home Health Care and the Housing and Living Arrangements of the Elderly, Journal of Urban Economics 62, 226-238.

Gleckman, Howard. 2007. “The Role of Private Insurance in Financing Long-Term Care” Center for Retirement Research September 2007, Number 7-13.

Goda, Gopi, 2011. The impact of state tax subsidies for private long-term care insurance on coverage and Medicaid expenditures, Journal of Public Economics 95, 744-757.

Komisar, Harriet L. and Lee Shirey Thompson. 2007. "National Spending for Long-Term Care.” Fact Sheet (February). Washington, DC: Georgetown University Long-Term Care Financing Project.

McCall, Nelda, Suzanne Driver, Ellen Bauer, and James Knickman, “The Partnership for Long Term Care: Who are the Partnership Policy Purchasers,” Medical Care Research and Review, Volume 54 Number 4 (December 1997): 472-489.

McCall, Nelda, Steven Mangle, Ellen Bauer, and James Knickman, 1998. "Factors important in the purchase of Partnership Long-Term Care Insurance, 33:2: 187-203.

McKnight, Robin, 2006. Home care reimbursement, long-term care utilization, and health 
outcomes. Journal of Public Economics 90, 293-323.

Moses, Stephen A. “The Long-Term Care Partnership Program: Why it Failed and How to Fix It” in Nelda McCall, editor, Who Will Pay for Long Term Care? Insights from the Partnership Program, Health Administration Press, Chicago, Illinois, 2001, pages 207222.

Munnell, Alicia and Mauricio Soto, “The House and Living Standards in Retirement.” Issue in Brief 39 (2005). Center for Retirement Research at Boston College.

National Association of Area Agencies on Again (n4a), 2011. Policy Priorities 2011.

Orsini, Chiara, 2010. Changing the way the elderly live: Evidence from the home health care market in the United States. Journal of Public Economics 94, 142-152.

Robert Wood Johnson Foundation, “Long-Term Care Partnership Expansion: A New Opportunity for States.” Issue Brief. May 2007.

Robert Wood Johnson Foundation, Health Policy Brief: The Class Act, May 2011. 
Table 1. Sample Statistics
(1)
(2)
(3)

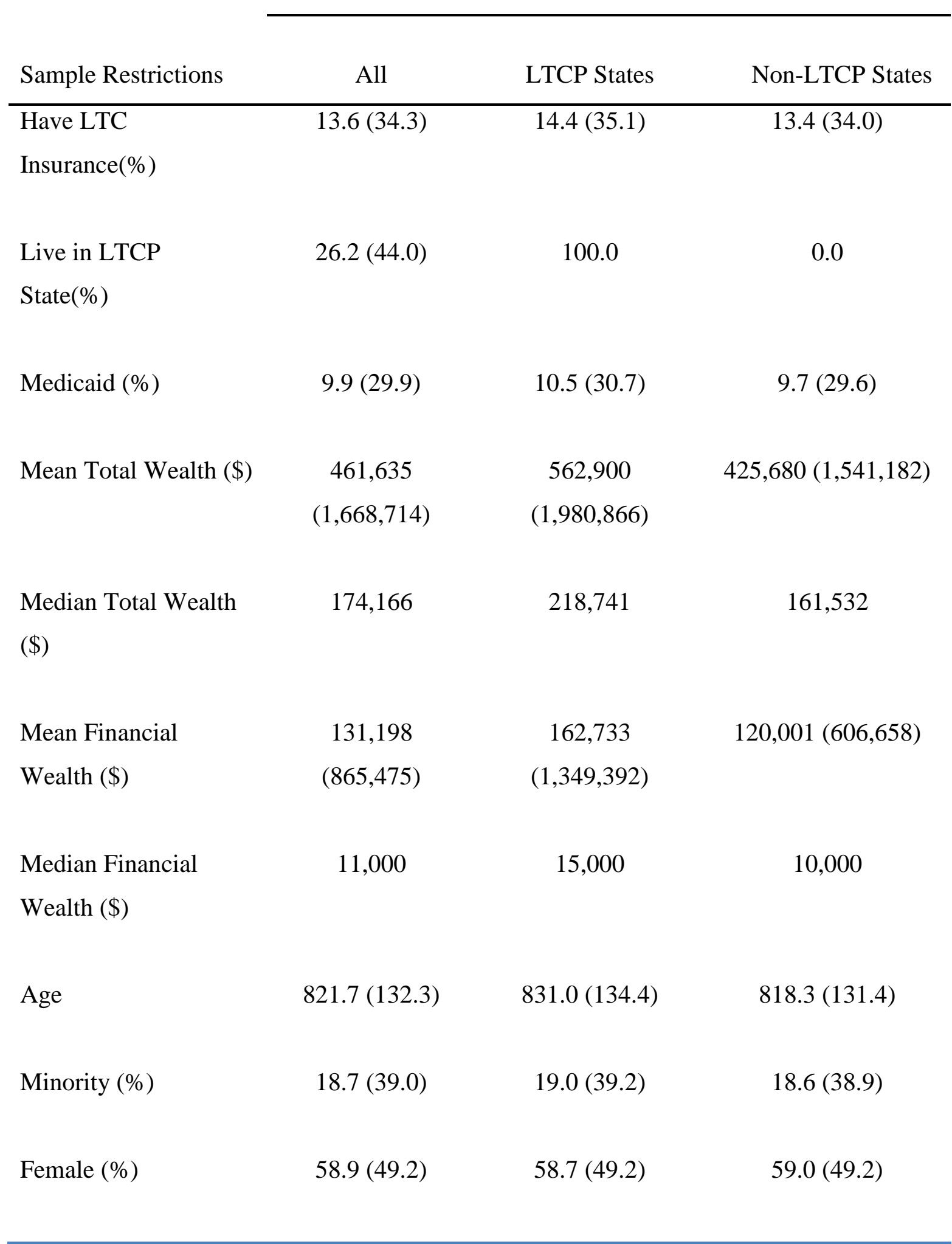


PRELIMINARY WORK: Please DO NOT CITE without permission from the author.

\begin{tabular}{lccc}
\hline Married (\%) & $65.3(47.6)$ & $64.5(47.9)$ & $65.6(47.5)$ \\
Kids & $3.24(2.18)$ & $3.2(2.1)$ & $3.3(2.2)$ \\
Sample Size & 24,584 & 13,108 & 11,476 \\
\hline
\end{tabular}

Note: These are sample statistics from the Health and Retirement Study (HRS) 2002-2008. Standard deviations are in parentheses. 
Table 2. Linear Probability Estimated Impact of Long-Term Care Partnership Programs on either $r$ or spouse having private long-term care insurance, (Standard Errors in Parentheses)

\begin{tabular}{|c|c|c|c|}
\hline \multirow{3}{*}{ Long-Term Care Insurance } & (1) & (2) & (3) \\
\hline & All & College or & High School or \\
\hline & & More & More \\
\hline \multirow[t]{3}{*}{ LTCP } & 0.004 & 0.009 & 0.006 \\
\hline & $(0.006)$ & $(0.009)$ & $(0.006)$ \\
\hline & [2.9\%] & {$[4.7 \%]$} & [3.7\%] \\
\hline \multirow[t]{3}{*}{ Married } & 0.071 & 0.090 & 0.078 \\
\hline & $(0.005)$ & $(0.008)$ & $(0.007)$ \\
\hline & {$[52.1 \%]$} & [47.3\%] & [48.1\%] \\
\hline \multirow[t]{3}{*}{ Kids } & -0.005 & -0.009 & -0.006 \\
\hline & $(0.001)$ & $(0.002)$ & $(0.002)$ \\
\hline & {$[-3.7 \%]$} & {$[-4.7 \%]$} & {$[-3.7 \%]$} \\
\hline \multirow[t]{3}{*}{ Female } & 0.012 & 0.019 & 0.015 \\
\hline & $(0.002)$ & $(0.006)$ & $(0.004)$ \\
\hline & [8.8\%] & {$[-10.0 \%]$} & {$[9.2 \%]$} \\
\hline \multirow[t]{3}{*}{ College } & 0.080 & & 0.063 \\
\hline & $(0.005)$ & & $(0.005)$ \\
\hline & [58.7\%] & & [38.8\%] \\
\hline \multirow[t]{3}{*}{ Minority } & -0.030 & -0.035 & -0.034 \\
\hline & $(0.007)$ & $(0.0011)$ & $(0.009)$ \\
\hline & {$[-22.0 \%]$} & {$[-18.4]$} & {$[-20.9 \%]$} \\
\hline Mean LTC policies (\%) & 13.63 & 19.04 & 16.23 \\
\hline
\end{tabular}


Number of Observations

71,522

28,886

50,756

Note: This table shows the estimated impact of living in a state with a LTC Partnership on buying a long-term care insurance policy, using linear probability estimation. The regressions also control for age and IADLs, but they are not shown in the tables above. A full set of fixed state and year effects are also included in all columns. Standard errors clustered by state and person identifier (using the Cameron, Gelbach, and Miller multi-dimension clustering technique) are presented in parentheses and marginal effects are shown in square brackets, which are the percentage point changes divided by the sample mean to get the percent changes.

Table 3. Linear Probability Estimated Impact of LTC Partnership Programs on Buying LTC insurance that covers nursing home care only or in-home care only for college graduates, (Standard Errors in Parentheses)

LTC insurance type

\begin{tabular}{lcccc}
\cline { 2 - 5 } LTC insurance type & $\begin{array}{c}\text { Nursing } \\
\text { Home Only }\end{array}$ & $\begin{array}{c}\text { Nursing Home } \\
\text { Only if have } \\
\text { LTC insurance }\end{array}$ & $\begin{array}{c}\text { In-Home } \\
\text { Care Only }\end{array}$ & $\begin{array}{c}\text { In-Home } \\
\text { Care Only if } \\
\text { have LTC } \\
\text { insurance }\end{array}$ \\
\hline LTCP & 0.003 & 0.016 & -0.005 & -0.021 \\
& $(0.003)$ & $(0.016)$ & $(0.003)$ & $(0.014)$ \\
& {$[13.5 \%]$} & {$[13.8 \%]$} & {$[-62.5 \%]$} & {$[-50.0 \%]$} \\
Married & 0.014 & 0.018 & 0.004 & 0.002 \\
\hline
\end{tabular}

In-Home 


\begin{tabular}{lcccc}
\hline & $(0.004)$ & $(0.011)$ & $(0.002)$ & $(0.010)$ \\
& {$[63.1 \%]$} & {$[15.5 \%]$} & {$[50.0 \%]$} & {$[-4.8 \%]$} \\
Kids & & & & \\
& -0.001 & -0.002 & 0.0002 & 0.002 \\
& $(0.001)$ & $(0.003)$ & $(0.0004)$ & $(0.002)$ \\
& {$[-4.5 \%]$} & {$[-1.7 \%]$} & {$[2.5 \%]$} & {$[4.8 \%]$} \\
Female & 0.005 & 0.019 & 0.004 & 0.015 \\
& $(0.002)$ & $(0.010)$ & $(0.001)$ & $(0.006)$ \\
& {$[-22.5 \%]$} & {$[16.3 \%]$} & {$[50.0 \%]$} & {$[35.7 \%]$} \\
Minority & -0.006 & -0.020 & 0.004 & 0.035 \\
& $(0.002)$ & $(0.011)$ & $(0.002)$ & $(0.011)$ \\
& {$[27.0 \%]$} & {$[-17.2 \%]$} & {$[50.0 \%]$} & {$[83.3 \%]$} \\
& & & & \\
Mean LTC Nursing & $2.22 \%$ & $11.64 \%$ & $0.80 \%$ & $4.2 \%$ \\
Home only & & & & \\
Number of Observations & 28,886 & 5,512 & 28,886 & 5,512 \\
& & & & \\
& & & & \\
\end{tabular}

Note: This table shows the estimated impact of living in a Long-Term Care Partnership state on what type of private long-term care insurance individuals bought for those with a college education or more. The excluded group consists of white males. The regressions also control for age and IADLs, but they are not shown in the tables above. A full set of fixed state and year effects are also included in all columns. A full set of state and year fixed effects are included in the estimation. Standard errors clustered by state and person identifier are shown in parentheses using the Cameron, Gelbach, and Miller estimation technique and marginal effects are shown in square brackets. Column (2) estimates conditional on buying a private long-term care insurance policy, what effect do LTCPs have on buying nursing hom only policies. Column (4) does the same but for in-home care only policies. 
Table 4. Linear Probability Estimated Impact of Long-Term Care Partnerships on using Medicaid Among College Graduates, (Standard Errors in Parentheses)

\begin{tabular}{lccc}
\hline \multirow{4}{*}{ Medicaid } & $(1)$ & $(2)$ & $(3)$ \\
\cline { 2 - 4 } & Either & Respondent & Spouse \\
& Use & Use & Use \\
& Medicaid & Medicaid & Medicaid \\
\hline LTCP & -0.009 & -0.009 & -0.005 \\
& $(0.004)$ & $(0.004)$ & $(0.004)$ \\
Married & {$[-18.2 \%]$} & {$[-22.0 \%]$} & {$[-24.0 \%]$} \\
& & & \\
& -0.035 & -0.057 & \\
Kids & $(0.004)$ & $(0.003)$ & \\
& {$[-70.6 \%]$} & {$[-139 \%]$} & \\
& & & \\
Female & 0.006 & 0.004 & 0.004 \\
& $(0.001)$ & $(0.0001)$ & $(0.001)$ \\
& {$[12.1 \%]$} & {$[9.8 \%]$} & {$[19.2 \%]$} \\
& & & \\
& -0.006 & 0.002 & 0.001 \\
& $(0.002)$ & $(0.002)$ & $(0.002)$ \\
& {$[-12.1 \%]$} & {$[4.9 \%]$} & {$[4.8 \%]$} \\
& & & \\
& 0.048 & 0.054 & 0.047 \\
& $(0.008)$ & $(0.006)$ & $(0.008)$ \\
& {$[96.8 \%]$} & {$[132 \%]$} & {$[226 \%]$} \\
\hline
\end{tabular}




\begin{tabular}{llll}
\hline Mean Medicaid Use & $4.96 \%$ & $4.10 \%$ & $2.08 \%$ \\
& & & \\
Number of Observations & 28,886 & 28,886 & 28,886
\end{tabular}

Note: This table shows the estimated impact of living in a state with a LTC Partnership on buying Medicaid use, using linear probability estimation. The regressions also control for age and IADLs, but they are not shown in the tables above. A full set of fixed state and year effects are also included in all columns. Standard errors clustered by state and person identifier (using the Cameron, Gelbach, and Miller multi-dimension clustering technique) are presented in parentheses and marginal effects are shown in square brackets, which are the percentage point changes divided by the sample mean to get the percent changes. 
Table 5. Individual Fixed Effects Model Among College Graduates

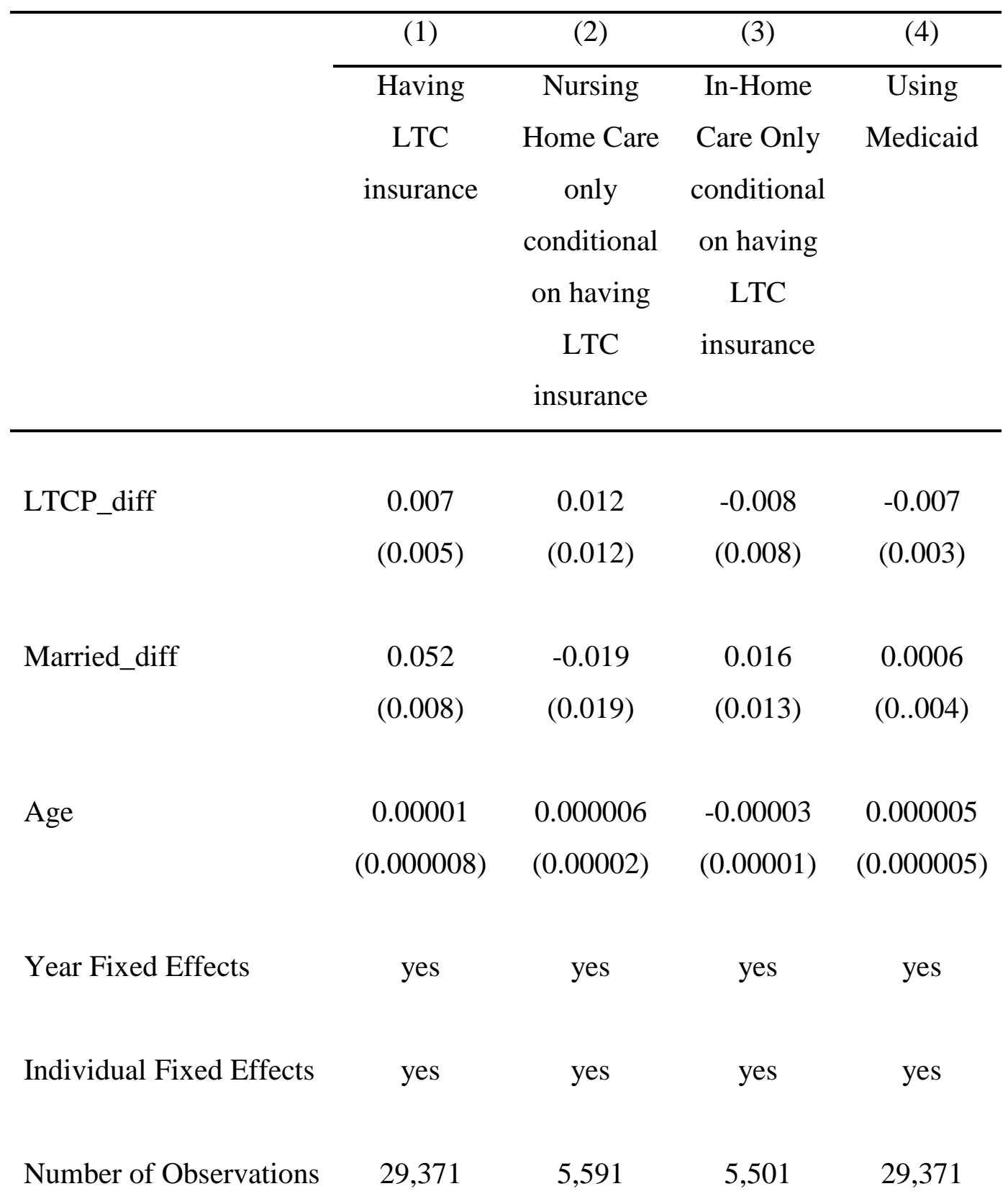

Note: This table uses an individual fixed effects model to estimate the effect of LTCPs on having long-term care insurance, the type of insurance purchased, and using Medicaid. 


\section{RECENT WORKING PAPERS FROM THE CENTER FOR RETIREMENT RESEARCH AT BOSTON COLLEGE}

How Important Is Asset Allocation to Financial Security in Retirement? Alicia H. Munnell, Natalia Sergeyevna Orlova, and Anthony Webb, April 2012

Great Recession-Induced Early Claimers: Who Are They? How Much Do They Lose? Matthew S. Rutledge and Norma B. Coe, April 2012

Effects of Employer Health Costs on the Trend and Distribution of Social Security-Taxable Wages

Gary Burtless And Sveta Milusheva, April 2012

Should Households Base Asset Decumulation Strategies on Required Minimum Distribution Tables?

Wei Sun and Anthony Webb, April 2012

Geographic Mobility Among Residents in Seniors Housing and Care Communities:

Evidence from the Residents Financial Survey

Norma B. Coe and April Yanyuan Wu, April 2012

Costs and Concerns among Residents in Seniors Housing and Care Communities: Evidence from the Residents Financial Survey

Norma B. Coe and April Yanyuan Wu, April 2012

Financial Well-Being of Residents in Seniors Housing and Care Communities: Evidence from the Residents Financial Survey

Norma B. Coe and April Yanyuan Wu, April 2012

Residents in Senior Housing and Care Communities: Overview of the Residents Financial Survey

Norma B. Coe and April Yanyuan Wu, April 2012

Social Security Claiming: Trends and Business Cycle Effects

Owen Haaga and Richard W. Johnson, February 2012

Economic Consequences of the Great Recession: Evidence from the Panel Study of Income Dynamics

Barry Bosworth, February 2012

The Changing Causes and Consequences of Not Working Before Age 62

Barbara A. Butrica and Nadia Karamcheva, February 2012

The Impact of Temporary Assistance Programs on Disability Rolls and Re-Employment Stephan Lindner and Austin Nichols, January 2012

All working papers are available on the Center for Retirement Research website (http://crr.bc.edu) and can be requested by e-mail (crr@bc.edu) or phone (617-552-1762). 